\title{
BMJ Open Temporal trends in severe morbidity and mortality associated with ectopic pregnancy requiring hospitalisation in Washington State, USA: a population- based study
}

\author{
Sarka Lisonkova, ${ }^{\oplus, 2,3}$ Justin Tan, ${ }^{1,2}$ Qi Wen, ${ }^{1,2}$ Lobna Abdellatif, ${ }^{1,2}$ \\ Lindsay L Richter, ${ }^{1,2}$ Sukainah Alfaraj, ${ }^{1,2}$ Paul J Yong, ${ }^{1,2}$ Mohamed A Bedaiwy ${ }^{1,2}$
}

To cite: Lisonkova S, Tan J, Wen $Q$, et al. Temporal trends in severe morbidity and mortality associated with ectopic pregnancy requiring hospitalisation in Washington State, USA: a populationbased study. BMJ Open 2019;9:e024353. doi:10.1136/ bmjopen-2018-024353

- Prepublication history and additional material for this paper are available online. To view please visit the journal (http:// dx.doi.org/10.1136/bmjopen2018-024353).

Received 23 May 2018 Revised 21 December 2018 Accepted 27 December 2018

Check for updates

(C) Author(s) (or their employer(s)) 2019. Re-use permitted under CC BY-NC. No commercial re-use. See rights and permissions. Published by BMJ.

${ }^{1}$ Department of Obstetrics and Gynaecology, University of British Columbia, Vancouver, British Columbia, Canada ${ }^{2}$ Children's and Women's Hospital and Health Centre of British Columbia, Vancouver, British Columbia, Canada

${ }^{3}$ School of Population and Public Health, University of British Columbia, Vancouver, British Columbia, Canada

Correspondence to Dr Sarka Lisonkova; slisonkova@cfri.ca

\section{ABSTRACT}

Objective To examine temporal trend in maternal mortality/severe morbidity associated with hospitalisation due to ectopic pregnancy.

Design A population-based observational study.

Setting and participants All women hospitalised for ectopic pregnancy in Washington State, USA, 1987-2014 ( $n=20418)$. The main composite outcome of severe morbidity/mortality included death, sepsis, need for transfusion, hysterectomy and systemic or organ failure, identified by diagnostic and procedure codes from hospitalisation files. Severe morbidity/ mortality due to ectopic pregnancy were expressed as incidence ratios among women of reproductive age (15-64 years) and among women hospitalised for ectopic pregnancy. Comparisons were made between 1987-1991 (reference) and 2010-2014 using ratios of incidence ratios (RR) and ratio differences $(\mathrm{RD})$. The Cochran-Armitage test for trend assessed statistical significance; logistic regression was used to obtain adjusted $\mathrm{OR}(\mathrm{AOR})$ and $95 \% \mathrm{Cl}$, adjusted for demographic factors and comorbidity.

Results Hospitalisation for ectopic pregnancy declined from 0.89 to 0.16 per 1000 reproductive age women between 1987-1991 and 2010-2014 ( $<<0.001)$. Among reproductive age women, ectopic pregnancy mortality remained stable (0.03 per 100000$)$; and mortality/severe morbidity increased among women aged $25-34$ years $(p=0.022)$. Among women hospitalised for ectopic pregnancy, mortality increased from 0.29 to 1.65 per 1000 between 1987-1991 and 2010-2015 $(p=0.06)$; severe morbidity/mortality increased from $3.85 \%$ to $19.63 \%(\mathrm{RR}=5.10,95 \% \mathrm{Cl} 4.36$ to $5.98 ; \mathrm{RD}=15.78$ per 100 women, $95 \% \mathrm{Cl} 13.90$ to 17.66 ; AOR for 1-year change was $1.08,95 \% \mathrm{Cl} 1.07$ to 1.08 ).

Conclusions Hospitalisation for ectopic pregnancy declined in Washington State, USA, between 1987 and 2014; however, mortality/severe morbidity associated with ectopic pregnancy increased in female population aged 25-34 years.

\section{INTRODUCTION}

Despite major advances in maternal and reproductive health in industrialised countries, ectopic pregnancy remains a significant cause of maternal mortality and accounts for

\section{Strengths and limitations of this study}

- Large, population-based data over the extended period of time.

- Consistent use of International Classification of Diseases, Version 9-Clinical Modification codes to identify ectopic pregnancy during the study period.

- Lack of information on individual treatment for ectopic pregnancy before hospitalisation.

- Lack of detailed clinical information on some risk factors, for instance, body mass index.

- Lack of information on the rates of ectopic pregnancy without hospitalisation.

$75 \%$ of maternal deaths in early pregnancy. ${ }^{12}$ While overall incidence is difficult to ascertain, population estimates suggest that rates of ectopic pregnancy increased in the USA from $0.4 \%$ of pregnancies in 1948 to approximately $2 \%$ of pregnancies in $2015 .^{2-4}$

An ectopic pregnancy is defined as a fertilised oocyte that implants outside of the uterine cavity. Such abnormal implantation occurs mostly in the fallopian tube and less frequently in the ovary, cervix or abdomen. While the underlying aetiology and pathogenesis are not completely understood, known risk factors include history of pelvic inflammatory disease, prior abdominal or pelvic surgery and in vitro fertilisation. ${ }^{5}$ The recurrence rate is approximately $18 \%$ among women with a prior fallopian tube pregnancy. ${ }^{6}$ Clinical signs include abdominal pain and vaginal bleeding in early pregnancy and diagnosis is made by pelvic ultrasound examination and by monitoring serum levels of human chorionic gonadotrophin (b-hCG). ${ }^{6}$ Both diagnostic modalities have improved significantly in the past 10 years with respect to ultrasound resolution and sensitivity of b-hCG detection. ${ }^{8-10}$ 
While surgical management was used in the past for definitive confirmation of diagnosis and treatment of ectopic pregnancy, recent improvements in early detection and diagnostic resolution have led to an increase in the proportion of women eligible for medical treatment with systemic methotrexate (MTX) ${ }^{11-13}$ However, MTX treatment is associated with moderate to severe side effects and relatively high failure rate (approximately 25\%) necessitating 'rescue' surgery and hospitalisation. ${ }^{14-17}$ As such, ectopic pregnancy continues to pose a significant public health concern ${ }^{18}$ and affects approximately 100000 women per year in the USA with an associated healthcare cost of estimated US $\$ 1$ billion. ${ }^{19} 20$

Despite the increased incidence of ectopic pregnancy and changing landscape of diagnosis and treatment, the impact of ectopic pregnancy on adverse maternal health outcomes has been understudied. The purpose of this study was to examine age-specific temporal trends in ectopic pregnancy requiring hospitalisation and associated rates of severe maternal morbidity/mortality.

\section{METHODS}

We carried out a population-based study including all women hospitalised for ectopic pregnancy in Washington State between 1987 and 2014. Hospitalisation data were obtained from the Comprehensive Discharge Abstract Database (CHARS), which includes all hospitalisations in Washington State and up to nine diagnostic and six procedure codes (International Classification of Diseases, Version 9-Clinical Modification (ICD-9-CM)) related to each hospitalisation episode. Ectopic pregnancy was identified using a previously validated algorithm consisting of specific diagnostic and procedure codes, namely the ICD-9-CM code '633' for ectopic pregnancy or any of the following inpatient procedure codes: ' 66.0 ' code for salpingotomy/salpingostomy, '66.62' code for salpingectomy with removal of tubal pregnancy and '74.3' code for removal of extratubal ectopic pregnancy. ${ }^{21}$ Information on death and severe morbidity during hospitalisation, age, chronic comorbidity, type of health insurance, length of hospital stay and cost was also obtained from the CHARS database. Women aged $<15$ years were excluded. US census data for Washington State in 1990, 2000 and 2010 and yearly intercensal age-specific population estimates were used to obtain age-specific data on female population in Washington State between 1987 and 2014. Age-specific data on the number of births per year in Washington State were obtained from publicly available reports. ${ }^{22}$ Information on the number of births among oldest women was available for age category 45 years or more.

\section{Outcome measures and covariates}

The primary outcome of severe morbidity or mortality was defined as a composite outcome which included maternal death during hospitalisation, or severe morbid conditions that were potentially life threatening, leading to serious sequelae, or requiring intensive care unit admission. Maternal death was identified from the CHARS database using the hospital discharge code for death, while ICD-9-CM diagnostic and procedure codes were used to identify women with severe morbidity. Severe morbid conditions were identified using a list of such conditions developed by the Canadian Perinatal Surveillance System. ${ }^{23}$ This included conditions with a high case fatality rate (eg, sepsis), and those associated with organ failure (eg, acute renal failure) or leading to adverse sequelae (eg, hysterectomy; see online supplementary appendix table S1). We included additional conditions recognised as severe maternal morbidity by the US Centre for Disease Control and Prevention, ${ }^{24}$ including need for life-saving procedures such as mechanical ventilation, conversion of cardiac rhythm, etc. Only conditions relevant to early pregnancy were included in the composite outcome. Severe morbidity was divided into the following five categories: (1) haemorrhage that required blood or other blood product transfusion; (2) sepsis; (3) hysterectomy; (4) severe morbidity denoted by the need for potentially life-saving procedures such as mechanical ventilation; and (5) other severe morbidity including respiratory morbidity (eg, respiratory arrest), thromboembolism (eg, deep venous thrombosis), cerebrovascular morbidity (eg, cerebral venous thromboembolism, intracranial haemorrhage), acute cardiac morbidity (eg, acute myocardial infarction, cardiac arrest, heart failure), renal or liver failure, shock and complications of anaesthesia and surgical interventions (eg, shock due to anaesthesia, cardiac and pulmonary complications). These categories were used to describe specific groups of severe morbid conditions and were not mutually exclusive (see online supplementary appendix table S1).

The type of health insurance was identified by the primary payer for hospitalisation, including the following categories: government or charity payer (Medicaid, Medicare, other government sponsored patients, and charity care), health maintenance organisation, private insurance (commercial insurance, labour and industries insurance and health services contractors insurance) and no insurance (self-pay). Comorbidity was identified by the ICD-9-CM codes and included chronic conditions as follows (see online supplementary appendix table S2): (1) cardiovascular diseases (eg, chronic hypertension, atherosclerosis); (2) respiratory diseases (eg, emphysema, asthma, chronic bronchitis); (3) diabetes mellitus; (4) endocrine system diseases (eg, hypothyroidism, ovarian dysfunction); (5) malignant or in situ neoplasms; (6) gastrointestinal disorders (eg, ulcers, Crohn's disease); (7) chronic genitourinary disorders (eg, chronic glomerulonephritis, chronic kidney diseases, endometriosis); (8) blood disorders (eg, anaemias, coagulation defects); (9) chronic neurological disorders (eg, multiple sclerosis, epilepsy); and (10) obesity. Acute conditions (eg, myocardial infarction) or those that could arise as a result of ectopic pregnancy or associated surgical procedures (eg, anaemia secondary to blood loss) were not included among chronic comorbid conditions. 


\section{Analysis}

Hospitalisation for ectopic pregnancy were calculated as ratios per 1000 women aged 15-64 years per year, and in age categories 15-24, 25-34 and 35-64 years. These ratios were also calculated per 1000 births per year among women 15 years of age or older and age-specific rates in categories $15-24,25-34$ and $\geq 35$ years to account for changes in fertility rates over time. All temporal trends were assessed using the Cochran-Armitage test for linear trend. Ratios were compared between time periods 19871991 and 2010-2014 using a ratio of these ratios (RR) and $95 \%$ CI. Ratio differences (RD) were calculated to express absolute differences in these ratios.

Logistic regression was used to assess temporal trends in severe morbidity/mortality among women hospitalised for ectopic pregnancy. OR expressed the average annual change in odds of severe morbidity/mortality. We anticipated that age distribution, type of health insurance and chronic comorbidity changed over time; hence, these factors were adjusted for in the regression models.

\section{Additional analyses}

Age-specific temporal trends in length of hospital stay and cost of hospitalisation were assessed throughout the study period and compared between 1987-1991 and 2010-14 using median and IQR. An inflation-adjusted cost was calculated using publicly available information on the US
Consumer Price Index for all Urban Consumers (CPI-U) with 1987 as a reference year. ${ }^{25}$

\section{Patient involvement}

Patients were not involved in setting the research questions or planning the study. Investigators do not know the identity of study participants.

All analyses were performed using publicly accessible deidentified data. An exemption from ethics approval was granted by the Department of Social and Health Services, State of Washington. Analyses were carried out using SAS V.9.4 (SAS Institute, Cary, North Carolina, USA).

\section{RESULTS}

Overall, 20418 women were hospitalised for ectopic pregnancy in Washington State between 1 January 1987 and 31 December 2014.

\section{Population ratios (per $\mathbf{1 0 0 0}$ women of reproductive age)}

Hospitalisation for ectopic pregnancy declined from 0.89 per 1000 women aged $15-64$ years in $1987-1991$ to 0.16 per 1000 women in $2010-2014$, RR 0.18 (95\% CI 0.17 to 0.19$)$, RD from -0.73 per 1000 women $(95 \% \mathrm{CI}$ -0.71 to -0.75 ; table 1$)$. This decline was largest among women aged 15-24 years (from 1.09 to 0.19 per 1000 women; RR 0.17 ; $95 \%$ CI 0.15 to 0.19 ; RD -0.90 per 1000

Table 1 Hospitalisation, death and severe morbidity due to ectopic pregnancy among women aged 15-64 years, Washington State, 1987-91 versus 2010-2014

\begin{tabular}{|c|c|c|c|c|c|}
\hline Year & 1987-1991 & 2010-2014 & RD (95\% Cl) & RR (95\% Cl) & P values* \\
\hline All women & $n=7815504$ & $\mathrm{n}=11214865$ & & & \\
\hline Hospitalisations per 1000 women & 0.89 & 0.16 & $-0.73(-0.71$ to -0.75$)$ & $0.18(0.17$ to 0.19$)$ & $<0.001$ \\
\hline $\begin{array}{l}\text { Death/severe morbidity per } 100000 \\
\text { women }\end{array}$ & 3.44 & 3.16 & $-0.28(-0.81$ to 0.25$)$ & 0.92 (0.78 to 1.07$)$ & 0.502 \\
\hline $\begin{array}{l}\text { Death/severe morbidity per } 100000 \\
\text { women }\end{array}$ & 2.74 & 3.16 & $0.42(-0.67$ to 1.51$)$ & 1.15 (0.79 to 1.68$)$ & 0.388 \\
\hline Women aged $25-34$ years & n=2 096794 & $n=2390244$ & & & \\
\hline Hospitalisations per 1000 women & 1.96 & 0.44 & $-1.52(-1.46$ to -1.59$)$ & $0.22(0.20$ to 0.23$)$ & $<0.001$ \\
\hline Hospitalisations per 1000 women & 0.27 & 0.06 & $-0.21(-0.19$ to -0.23$)$ & $0.22(0.20$ to 0.25$)$ & $<0.001$ \\
\hline $\begin{array}{l}\text { Death/severe morbidity per } 100000 \\
\text { women }\end{array}$ & 1.64 & 1.37 & $-0.27(-0.75$ to 0.21$)$ & $0.82(0.61$ to 1.14$)$ & 0.92 \\
\hline
\end{tabular}

RR denotes ratio of hospitalisation and mortality/morbidity ratios.

The RRs are presented to demonstrate the change between the extreme periods. The RR may not be statistically significant because only cases occurring in these two time periods are included; thus, the power to detect a statistically significant association is lower as compared with the Cochran-Armitage test for trend (that included all cases of mortality/morbidity and all population over the study period). ${ }^{*} \mathrm{P}$ value based on the Cochran-Armitage test for trend.

$\mathrm{RD}$, ratio difference. 

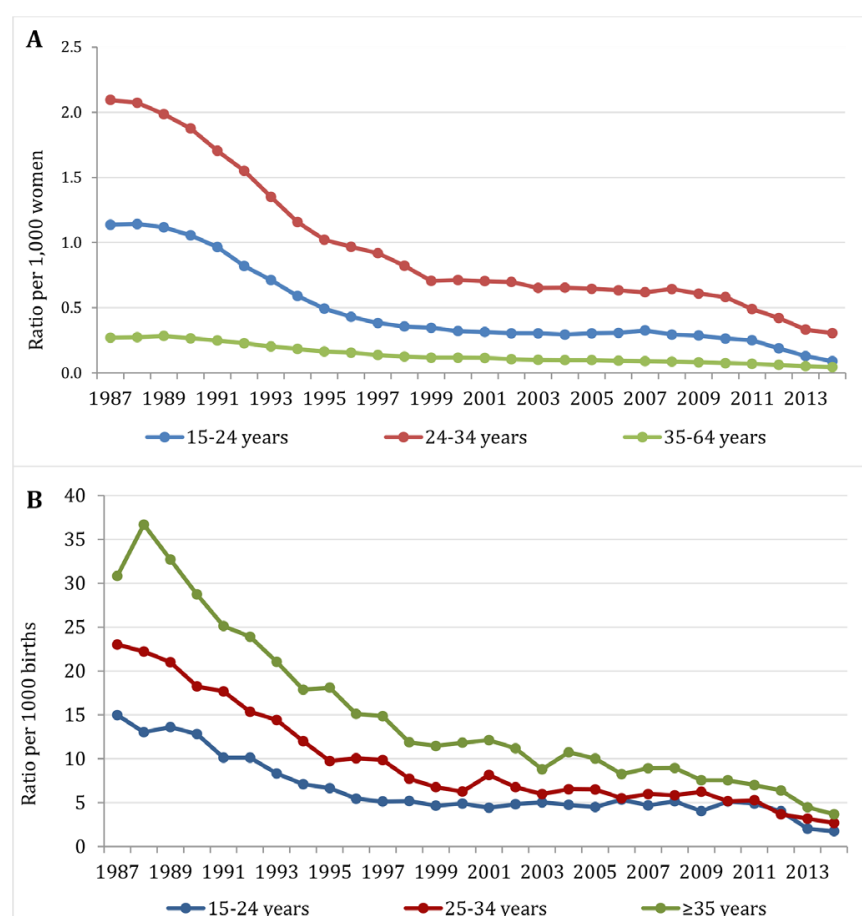

Figure 1 Age-specific ratios of hospitalisation for ectopic pregnancy $(A)$ per 1000 women (3-year moving average) and (B) per 1000 births. Washington State, 1987-2014.

women, $95 \%$ CI from -0.85 to -0.96 ; figure 1$)$. In-hospital mortality remained unchanged during this period, and no significant trend was observed for mortality/ severe morbidity among women aged 15-24 years and 35-64 years (table 1). A significant temporal increase in mortality/severe morbidity was observed among women

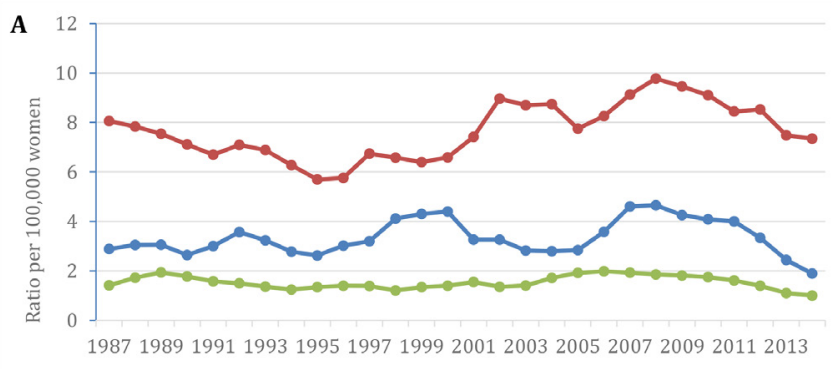

$\rightarrow$ 15-24 years $\rightarrow$ 24-34 years $\rightarrow$ 35-64 years

$$
\text { B }
$$

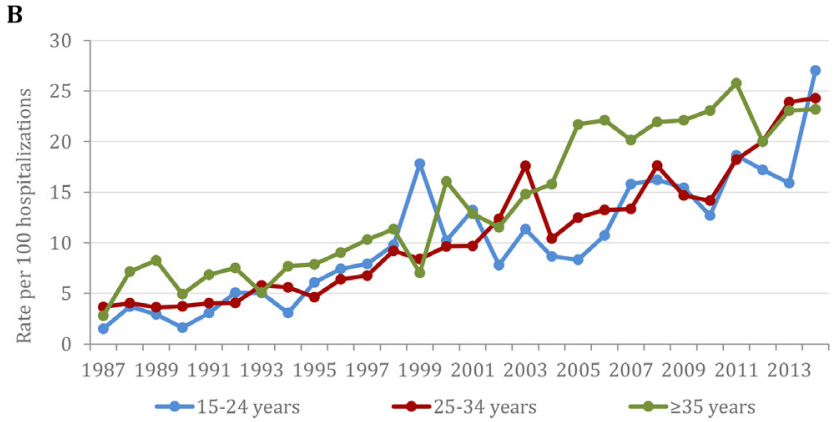

Figure 2 Age-specific ratios of death/severe morbidity due to ectopic pregnancy (A) per 100000 women (3-year moving average) and (B) per 100 hospitalised women. Washington State, 1987-2014. aged 25-34 years $(\mathrm{p}=0.022)$; this increase was apparent mainly after 1995 (figure 2). The contrast between population ratios in mortality/severe morbidity among these women between 1987-1991 and 2010-2014 (7.49 vs 7.99 per 100000 women) yielded RR of 1.07 (95\% CI 0.86 to 1.32). The RR was not statistically significant because only cases occurring in these two time periods were included, thus the power to detect a statistically significant association was lower as compared with the Cochran-Armitage test for trend (that includes all cases of mortality/ morbidity and all population over the study period; a $\mathrm{p}$ value for trend was 0.022 ).

In addition, hospitalisations per 1000 women aged 15-49 years (the WHO definition of reproductive age) declined from 1.11 per 1000 in 1987-1991 to 0.23 per 1000 in $2010-2014$ (RR $0.20,95 \%$ CI 0.19 to 0.21 ; data not shown).

\section{Ratios per 1000 births}

Hospitalisation for ectopic pregnancy declined dramatically from 18.54 per 1000 births in $1987-1991$ to 4.18 per 1000 births in 2010-2014 (table 2). The decline was observed in all age groups between these periods: among women aged 15-24 years, the decline was from 12.87 to 3.64 per 1000 births; among women 25-34, the ratios fell from 20.35 to 3.96 per 1000 births, and among women $\geq 35$ years from 30.40 to 5.76 per 1000 births, respectively (figure 1). The RRs contrasting these two periods were 0.28 (95\% CI 0.25 to 0.32 ) in women $15-24$ years, RR 0.19 (95\% CI 0.18 to 0.21$)$ in women $25-34$ years and RR 0.19 (95\% CI 0.17 to 0.21 ) in women aged $\geq 35$ years (RDs are presented in table 2). All temporal trends were statistically significant $(\mathrm{p}<0.001)$.

\section{Adverse outcomes among hospitalised women}

The overall case fatality rate increased from 0.29 per 1000 in 1987-1991 to 1.65 per 1000 women hospitalised for ectopic pregnancy in 2010-2014 (RR 5.69, 95\% CI 0.96 to 34.50 ; RD -1.36 per 1000 women, $95 \%$ CI from -3.27 to 0.50 ), while the rate of the composite outcome (severe morbidity or mortality) increased from $3.85 \%$ to $19.63 \%$ (figure 2, table 2). The youngest women had the largest increase in severe morbidity (RR 6.75, 95\% CI 4.72 to 9.66) compared with women 25-34 (RR 5.06, 95\% CI 4.15 to 6.18 ) and women $\geq 35$ years (RR $3.74,95 \%$ CI 2.80 to 5.01; RDs are presented in table 2).

The most common complication was need for blood or blood product transfusion $(73.4 \%$ of any severe morbidity; table 3). A significant temporal increase was observed for rates of sepsis and blood transfusion (both $\mathrm{p}<0.001)$. The increase in the blood transfusion rate was observed in all age groups, while the increase in the sepsis rate was observed only in women aged 25-34 and $\geq 35$ years (data not shown). The prevalence of underlying chronic conditions increased over time, from $4.54 \%$ in $1987-91 \%$ to $22.21 \%$ in $2010-2014$ ( $\mathrm{p}<0.001$; see online supplementary appendix figure $\mathrm{S} 1$ ). 
Table 2 Hospitalisations for ectopic pregnancy per 1000 births and severe morbidity and mortality among hospitalised women; Washington State, 1987-1991 versus 2010-2014

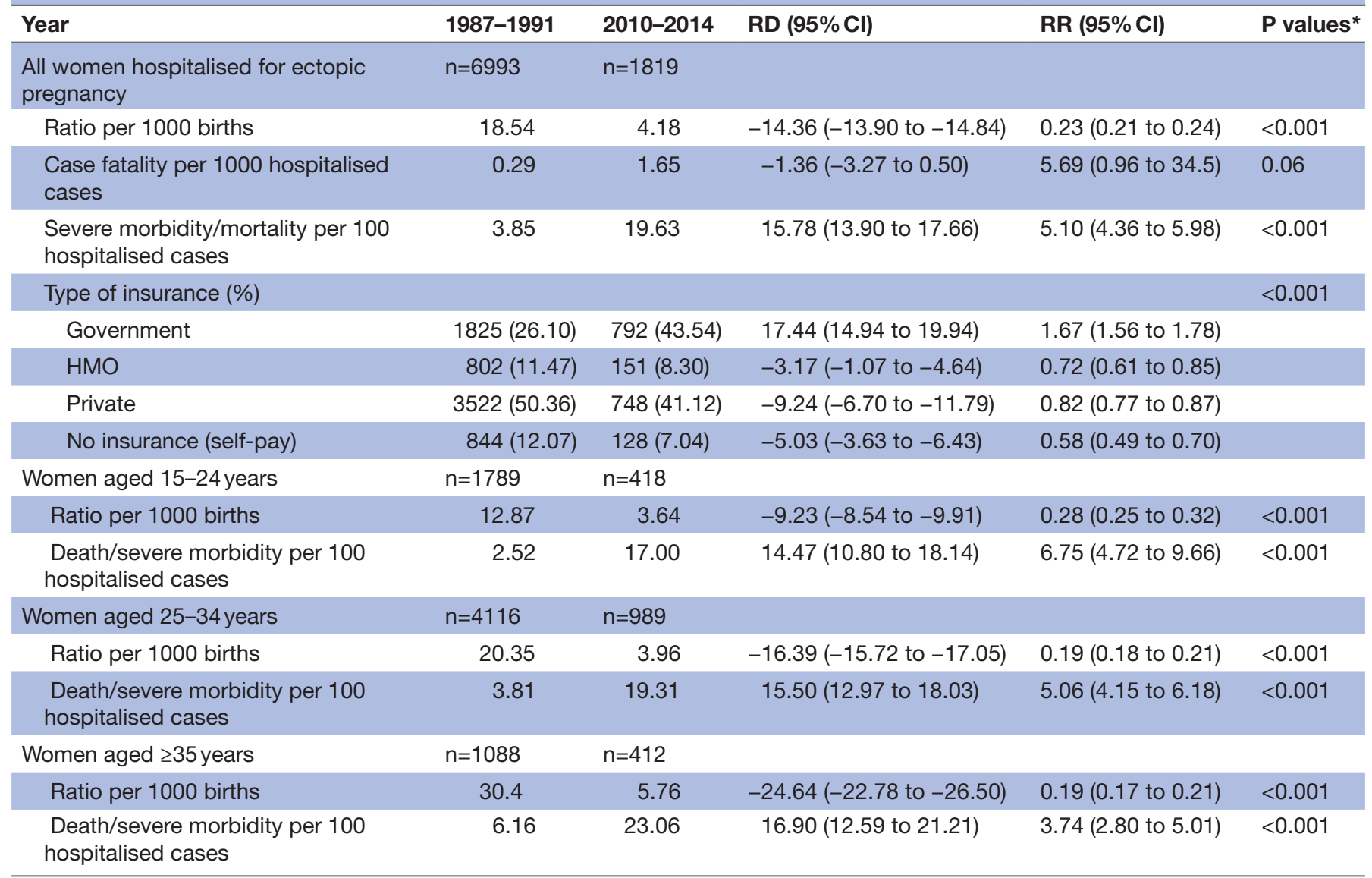

$\mathrm{RR}$ denotes ratio of hospitalisation and death/severe morbidity ratio.

${ }^{*} P$ value based on the Cochran-Armitage test for linear trend.

$\mathrm{HMO}$, health maintenance organisation; RD, ratio difference.

\section{Multivariable analyses}

Regression analyses showed that the unadjusted increase in odds of the composite outcome (severe morbidity/ mortality) associated with hospitalisation for ectopic pregnancy was on average 9\% per year (OR 1.09, 95\% CI 1.08 to 1.09 ; table 4 ). After adjusting for age, type of health insurance and chronic comorbidity, the increase in odds of the composite outcome was on average $8 \%$ per year (adjusted OR (AOR) 1.08, 95\% CI 1.07 to 1.08 ). Factors significantly associated with elevated odds of severe morbidity/mortality were: older age ( $\geq 35$ years vs 25-34 years; AOR 1.41, 95\% CI 1.25 to 1.60$)$, genitourinary chronic condition (AOR $1.72 ; 95 \%$ CI 1.36 to 2.18 ), neoplasms (AOR 4.21, 95\% CI 1.93 to 9.16); chronic blood disorders (AOR 4.77, 95\% CI 3.79 to 6.01 ) and obesity (AOR 1.59, 95\% CI 1.18 to 2.15 ).

Table 3 Severe morbidity associated with hospitalisation for ectopic pregnancy; Washington State, 1987-2014

\begin{tabular}{|c|c|c|c|c|c|c|c|c|}
\hline \multirow[b]{2}{*}{ Death/Severe morbidity } & \multicolumn{2}{|l|}{ All women } & \multicolumn{2}{|c|}{ 15-24 years } & \multicolumn{2}{|l|}{ 25-34 years } & \multicolumn{2}{|l|}{$\geq 35$ years } \\
\hline & $\mathbf{N}(\%)$ & Rate* $^{*}$ & $\mathbf{N}(\%)$ & Rate $^{*}$ & $\mathbf{N}(\%)$ & Rate $^{*}$ & N (\%) & Rate $^{*}$ \\
\hline Blood transfusion & $1243(73.42)$ & 6.09 & $284(81.38)$ & 5.70 & $661(75.11)$ & 5.81 & $298(64.22)$ & 7.33 \\
\hline Hysterectomy & 203 (11.99) & 0.99 & $9(2.58)$ & 0.18 & $78(8.86)$ & 0.69 & $116(25)$ & 2.85 \\
\hline Other potentially life-saving interventions & 335 (19.79) & 1.64 & $39(11.17)$ & 0.78 & $150(17.05)$ & 1.32 & $146(31.47)$ & 3.59 \\
\hline Death & $7(0.41)$ & 0.03 & $1(0.29)$ & 0.02 & $3(0.34)$ & 0.03 & $3(0.65)$ & 0.07 \\
\hline Death/severe morbidity & 1782 & 8.73 & 373 & 7.49 & 920 & 8.09 & 489 & 12.02 \\
\hline
\end{tabular}

${ }^{*}$ Rate per 100 hospitalised women. 
Table 4 Adjusted temporal trend in death/severe morbidity associated with hospitalisation for ectopic pregnancy; Washington State, 1987-2014

\begin{tabular}{ll}
\hline Risk factor & AOR (95\% Cl) \\
\hline Year & $1.08(1.07$ to 1.08$)$ \\
\hline Age $15-24$ years $^{\star}$ & $0.92(0.81$ to 1.05$)$ \\
\hline Age $\geq 35$ years $^{*}$ & $1.41(1.25$ to 1.60$)$ \\
\hline Hypertensive chronic disease & $1.38(0.90$ to 2.10$)$ \\
\hline Respiratory chronic disease & $0.81(0.58$ to 1.13$)$ \\
\hline Endocrine chronic disease & $1.17(0.80$ to 1.71$)$ \\
\hline Diabetes mellitus & $0.97(0.53$ to 1.78$)$ \\
\hline Gastrointestinal chronic disease & $0.92(0.31$ to 2.72$)$ \\
\hline Genitourinary chronic disease & $1.72(1.36$ to 2.18$)$ \\
\hline Malignant/in situ neoplasm & $4.21(1.93$ to 9.16$)$ \\
\hline Blood disorder & $4.77(3.79$ to 6.01$)$ \\
\hline Neurological disorder & $1.01(0.47$ to 2.17$)$ \\
\hline Obesity & $1.59(1.18$ to 2.15$)$ \\
\hline Government insurance $\dagger$ & $1.07(0.89$ to 1.29$)$ \\
\hline HMO† & $0.76(0.60$ to 0.96$)$ \\
\hline Private insurance $\dagger$ & $1.00(0.83$ to 1.20$)$ \\
\hline
\end{tabular}

${ }^{*}$ Reference category: no insurance coverage (self-pay). †Reference: age 25-34 years.

AOR, adjusted OR (an average increase in odds of death/severe morbidity per year); HMO, health maintenance organisation.

\section{Additional analyses}

The median length of hospital stay was 2 days and the IQR (q-range) was 1 and 3 days (see online supplementary appendix table S3). The median length of stay declined from 3 days (q-range: 3 and 4 days) in 1987-1991 to 1 day (q-range: 1 and 2 days) in 2010-2014. The overall median cost per hospital stay was US $\$ 5444$ (q-range US $\$ 3501$ to US $\$ 10433$ ); the cost differed by age and was highest among women aged $\geq 35$ years in 2010-2014 (see online supplementary appendix table S3). The median cost per hospital stay increased from US\$3236 in 1987-1991 (q-range US\$2557 and US\$4.087) to US\$24661 (q-range US\$16934 and US\$34 794) in 2010-2014. Similar trends were observed in all age groups (see online supplementary appendix figure S2). Inflation-adjusted cost per hospital stay almost quadrupled during the study period (from median cost US\$3236 in 1987-1991 to US\$12635 in 2010-2014, adjusted to CPI-U in 1987; see online supplementary appendix table S3 and figure S2).

\section{DISCUSSION}

Our study shows that while hospitalisation for ectopic pregnancy declined in Washington state between 1987 and 2014, severe maternal morbidity/mortality among hospitalised women increased. These trends were independent of temporal changes in maternal age, type of health insurance and underlying chronic morbidity.
Severe maternal morbidity/mortality among reproductive-age women remained unchanged. While the median length of hospital stay declined, the inflation-adjusted cost associated with hospitalisation for ectopic pregnancy increased approximately fourfold.

Ectopic pregnancy carries a considerable physical, psychological and social burden. ${ }^{18}$ The complications can be serious, ${ }^{26}$ and the treatment and recovery process among women with severe complications is frequently accompanied by anxiety, depression and even elements of post-traumatic stress. ${ }^{27}$ Over the past few decades, there has been greater awareness of ectopic pregnancy and improvements in diagnostic modalities including highly sensitive b-hCG testing and high-resolution ultrasound examination, all of which has enabled earlier diagnosis and a shift towards non-surgical outpatient MTX treatment. ${ }^{11} 17$ Our findings support this trend by showing a large temporal decline in hospitalisation due to ectopic pregnancy.

The concomitant significant increase in severe maternal morbidity and mortality among hospitalised women is likely a result of increased acuity of women admitted for ectopic pregnancy complications. However, the increase in morbidity was not explained by changes in maternal age, type of health insurance and underlying chronic diseases; thus, it is possible that some women have not benefitted from early diagnosis and medical treatment. This may be because of specific patient or physician preferences for care, or due to altered clinical symptoms that were not indicative of ectopic pregnancy in early stages. MTX treatment failure may also result in delayed surgical intervention and increased acuity of hospitalised patients. ${ }^{9}{ }^{15}$ Increasingly more liberal MTX treatment among women in later gestation and with higher b-hCG levels ${ }^{14}$ may have also led to higher rates of medical treatment failure and resulting complications from delayed resolution of ectopic pregnancy including tubal rupture and hemoperitoneum. ${ }^{11} 1415$ This theory is supported by our findings that demonstrated an increase in complications in women of all age groups, types of health insurance and chronic morbidity. Nevertheless, an increasingly higher proportion of low-risk women with ectopic pregnancy is successfully treated with MTX in the outpatient settings, which likely contributed to temporal increase in mortality/morbidity in hospitalised women. Population analysis shows, however, that despite the improvement in diagnosis and changes in treatment methods, mortality and severe morbidity remained unchanged among women of reproductive age.

Our results are consistent with previous studies showing a decline in inpatient hospitalisation for ectopic pregnancy. ${ }^{11}{ }^{18}$ Prior studies were insurance-based or hospital-based and therefore less generalisable as compared with our study. Our study also benefits from a large population database spanning over 25 years and consistent ascertainment of ectopic pregnancy over the study period (ICD-9-CM diagnostic and procedure codes). We assume that all women with severe morbidity due to 
ectopic pregnancy would be hospitalised; thus, the population ratios are reflective of the risk of severe maternal morbidity due to this condition among reproductive-age women regardless of the rate of ectopic pregnancy or fertility.

This study has several limitations. First, the data source lacked information on women with ectopic pregnancy who were successfully treated in outpatient settings, precluding comparisons of overall ectopic pregnancy ratios. As a result, the case fatality rate reported in this study reflects only case fatality among hospitalised women, and is higher than expected if all women with ectopic pregnancy were included. Mortality due to ectopic pregnancy among all women of reproductive age were not influenced by changes in hospitalisations for ectopic pregnancy. Second, women who died from complications of ectopic pregnancy prior to hospitalisation or in the emergency room were not captured in our study, which may underestimate the number of deaths. Third, we could not ascertain any treatment prior to hospital admission; thus, the reasons behind each hospitalisation were not clear with respect to a possible failure of prior MTX therapy or delay in ectopic pregnancy recognition. Fourth, we could not account for repeated hospitalisations due to ectopic pregnancy in individual women, and we did not have information on race, education, marital status, body mass index, smoking and other risk factors for severe morbidity that may have changed over time. Fifth, women from racial/ethnic minority groups and those lacking prepregnancy and prenatal care are at increased risk of ectopic pregnancy complications. ${ }^{28-30}$ We did not have specific information on ethnicity and prepregnancy/prenatal care, which is a limitation of this study. Last, some errors in coding are inherent to all large databases. The CHARS database has been previously validated for pregnancy-related complications and prepregnancy chronic conditions, ${ }^{31} 32$ and the data collection process includes quality checks and an annual report to monitor for possible overdiagnosis of certain conditions. ${ }^{33}{ }^{34}$ Nevertheless, some chronic medical conditions may be under=reported (eg, obesity).

\section{CONCLUSION}

While hospitalisations for ectopic pregnancy decreased substantially, ectopic pregnancy remains a major cause of severe maternal morbidity among hospitalised women. Our results suggest that improvements in diagnosis and changes in treatment modalities during the past decades have translated into significant decline in hospitalisations; however, population ratios of severe morbidity due to ectopic pregnancy remained unchanged and increased among women aged 25-34 years. Further improvements in diagnosis and treatment as well as a better understanding of the pathogenesis of ectopic pregnancy are needed in order to reduce the overall burden of this condition. Healthcare providers should be aware of age-related risks of severe morbidity and mortality in women hospitalised for ectopic pregnancy and future prospective studies should investigate additional predictors of serious complications.

Contributors SL designed the study, SL and QW performed data analysis and SL wrote the first draft of the manuscript. JT, LA, LLR, SA, PJY and MAB contributed to the interpretation of results and critically revised this first draft. All authors approved the final version of the manuscript.

Funding SL is supported by a Scholar Award from the Michael Smith Foundation for Health Research. This work was supported by the CIHR grant F17-02161.

Competing interests None declared.

Patient consent for publication Not required.

Ethics approval All analyses were performed on publicly accessible de-identified data. An exemption from ethics approval was granted by the Department of Social and Health Services, State of Washington.

Provenance and peer review Not commissioned; externally peer reviewed.

Data sharing statement Analyses were based on administrative data collected and maintained by the Department of Health, State of Washington. The availability of the data is restricted. Permission for data access can granted after verification of the research goals by the Department of Social and Health Services, State of Washington.

Author note Hospitalization for ectopic pregnancy declined in Washington State, USA, between 1987 and 2014, while the cost and associated morbidity among hospitalised women increased.

Open access This is an open access article distributed in accordance with the Creative Commons Attribution Non Commercial (CC BY-NC 4.0) license, which permits others to distribute, remix, adapt, build upon this work non-commercially, and license their derivative works on different terms, provided the original work is properly cited, appropriate credit is given, any changes made indicated, and the use is non-commercial. See: http://creativecommons.org/licenses/by-nc/4.0/.

\section{REFERENCES}

1. Creanga AA, Shapiro-Mendoza CK, Bish CL, et al. Trends in ectopic pregnancy mortality in the United States: 1980-2007. Obstet Gynecol 2011;117:837-43.

2. Centers for Disease Control and Prevention (CDC). Ectopic pregnancy--United States, 1990-1992. MMWR Morb Mortal Wkly Rep 1995;44:46-8.

3. Coste J, Bouyer J, Job-Spira N. [Epidemiology of ectopic pregnancy: incidence and risk factors]. Contracept Fertil Sex 1996;24:135-9.

4. Stulberg DB, Cain LR, Dahlquist I, et al. Ectopic pregnancy rates in the Medicaid population. Am J Obstet Gynecol 2013;208:274. e1-274.e7.

5. Farquhar CM. Ectopic pregnancy. Lancet 2005;366:583-91.

6. Madhra M, Horne AW. Ectopic pregnancy. Obstetrics, Gynaecology \& Reproductive Medicine 2014;24:215-20.

7. Sivalingam VN, Duncan WC, Kirk E, et al. Diagnosis and management of ectopic pregnancy. J Fam Plann Reprod Health Care 2011;37:231-40.

8. Sowter MC, Farquhar CM. Ectopic pregnancy: an update. Curr Opin Obstet Gynecol 2004;16:289-93.

9. Zane SB, Kieke BA, Kendrick JS, et al. Surveillance in a time of changing health care practices: estimating ectopic pregnancy incidence in the United States. Matern Child Health J 2002;6:227-36

10. van Mello NM, Mol F, Ankum WM, et al. Ectopic pregnancy: how the diagnostic and therapeutic management has changed. Fertil Steril 2012;98:1066-73.

11. Hsu JY, Chen L, Gumer AR, et al. Disparities in the management of ectopic pregnancy. Am J Obstet Gynecol 2017;217:49.e1-49.e10.

12. Carson SA, Buster JE. Ectopic pregnancy. N Engl J Med 1993;329:1174-81.

13. Bedaiwy MA, Escobar PF, Pinkerton J, et al. Laparoendoscopic single-site salpingectomy in isthmic and ampullary ectopic pregnancy: preliminary report and technique. J Minim Invasive Gynecol 2011;18:230-3.

14. Barnhart KT, Gosman G, Ashby R, et al. The medical management of ectopic pregnancy: a meta-analysis comparing "single dose" and "multidose" regimens. Obstet Gynecol 2003;101:778-84.

15. Lipscomb GH, McCord ML, Stovall TG, et al. Predictors of success of methotrexate treatment in women with tubal ectopic pregnancies. N Engl J Med 1999;341:1974-8. 
16. Yao M, Tulandi T, Kaplow M, et al. A comparison of methotrexate versus laparoscopic surgery for the treatment of ectopic pregnancy: a cost analysis. Hum Reprod 1996;11:2762-6.

17. Hoover KW, Tao G, Kent CK. Trends in the diagnosis and treatment of ectopic pregnancy in the United States. Obstet Gynecol 2010;115:495-502.

18. Trabert B, Holt VL, Yu O, et al. Population-based ectopic pregnancy trends, 1993-2007. Am J Prev Med 2011;40:556-60.

19. Washington AE, Katz P. Ectopic pregnancy in the United States: economic consequences and payment source trends. Obstet Gynecol 1993;81:287-92.

20. Papillon-Smith J, Imam B, Patenaude V, et al. Populationbased study on the effect of socioeconomic factors and race on management and outcomes of 35,535 inpatient ectopic pregnancies. $J$ Minim Invasive Gynecol 2014;21:914-20.

21. Scholes D, Yu O, Raebel MA, et al. Improving automated case finding for ectopic pregnancy using a classification algorithm. Hum Reprod 2011;26:3163-8.

22. Washington State Department of Health. All birth tables by year. 2017. https://www.doh.wa.gov/DataandStatisticalReports/ VitalStatisticsData/Birth/BirthTablesbyYear (Accessed 26 Jul 2017).

23. Joseph KS, Liu S, Rouleau J, et al. Severe maternal morbidity in Canada, 2003 to 2007: surveillance using routine hospitalization data and ICD-10CA codes. J Obstet Gynaecol Can 2010;32:837-46.

24. Centers for Disease Control and Prevention. Severe maternal morbidity in the United States. 2013. http://www.cdc.gov/ reproductivehealth/maternalinfanthealth/severematernalmorbidity. html (Accessed 4 Oct 2018).

25. US Inflation Calculator. Consumer Price Index Data from 1913 to 2018. http://www.usinflationcalculator.com/inflation/consumer-priceindex-and-annual-percent-changes-from-1913-to-2008/ (Accessed 6 Oct 2018).

26. Filho EAR, Santana DS, Cecatti JG, et al. Awareness about a life-threatening condition: ectopic pregnancy in a network for surveillance of severe maternal morbidity in Brazil. BioMed Research International 2014;2014:1-8.

27. Farren J, Jalmbrant M, Ameye L, et al. Post-traumatic stress, anxiety and depression following miscarriage or ectopic pregnancy: a prospective cohort study. BMJ Open 2016;6:e011864.

28. Stulberg DB, Cain L, Hasham Dahlquist I, Dahlquist IH, et al. Prepregnancy and early prenatal care are associated with lower risk of ectopic pregnancy complications in the medicaid population: 200408. Paediatr Perinat Epidemiol 2017;31:4-10.

29. Stulberg DB, Zhang JX, Lindau ST. Socioeconomic disparities in ectopic pregnancy: predictors of adverse outcomes from Illinois hospital-based care, 2000-2006. Matern Child Health J 2011;15:234-41.

30. Stulberg DB, Cain L, Dahlquist IH, et al. Ectopic pregnancy morbidity and mortality in low-income women, 2004-2008. Hum Reprod 2016;31:666-71.

31. Lydon-Rochelle MT, Holt VL, Cárdenas V, et al. The reporting of preexisting maternal medical conditions and complications of pregnancy on birth certificates and in hospital discharge data. Am J Obstet Gynecol 2005;193:125-34.

32. Lydon-Rochelle MT, Holt VL, Nelson JC, et al. Accuracy of reporting maternal in-hospital diagnoses and intrapartum procedures in Washington State linked birth records. Paediatr Perinat Epidemiol 2005;19:460-71.

33. CHARS Reports. Hospital inpatient discharge database reports 2010-2016. http://www.doh.wa.gov/ForPublicHealthandHealthcare Providers/HealthcareProfessionsandFacilities/DataReportingand Retrieval/HospitallnpatientDatabaseCHARS (Accessed October 6, 2018).

34. Washington State Department of Health Comprehensive Abstract Reporting System. Procedure manual for submitting discharge

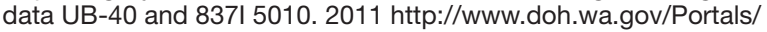
1/Documents/5300/CHARS-UB04-5010-CompanionGuide-R5.pdf (Accessed October 6, 2018). 